\title{
MODELO MATEMÁTICO DO ESCOAMENTO NO INTERIORDESGASEIFICADOR RH: ANÁLISE DO COMPORTAMENTO DA ESCÓRIA PELO SISTEMA AR/ÓLEO/ÁGUA*
}

\author{
Leonardo Neves ${ }^{1}$ \\ Roberto Parreiras Tavares ${ }^{2}$
}

\begin{abstract}
Resumo
No presente trabalho foi feito um estudo do escoamento multifásico do desgaseificador $\mathrm{RH}$ através do no sistema água/óleo/ar. A modelagem matemática do escoamento fluidodinâmico foi feito utilizando a abordagem de dois fluidos Euleriana-Euleriana. No estudo foi empregado o modelamento matemático para simular as vazões empregadas na indústria para prever o comportamento da escória. Os experimentos foram feitos utilizando o modelo físico do desgaseificador $\mathrm{RH}$ da USIMINAS nas escalas de 1:5. Através de filmagens utilizando câmera comum e cálculos de espessura do óleo pôde-se validar os resultados obtidos no modelamento matemático. Foi determinado que na camada de óleo entre a panela e as pernas de descida e de subida do desgaseificador $\mathrm{RH}$ foram as regiões que possuem a menor espessura da camada de óleo. Os resultados apontaram que a espessura do óleo entre a perna de subida e a panela a espessura do óleo são as menores e decrescem à medida que a vazão de gás aumenta.
\end{abstract}

Palavras-chave: Desgaseificador RH; Escoamento multifásico; Espessura da escória.

\section{MATHEMATICAL MODEL OF FLOW IN THE RH DEGASSER: ANALYSIS OF BEHAVIOR OF SLAG BY SYSTEM AIR/OIL/WATER}

\section{Abstract}

In this paper a study of multiphase flow in the $\mathrm{RH}$ degasser was developed. The mathematical simulations in physical model were performed using the Eulerian approach to simulate the flow rates employed in the industry to predict the behavior of slag. For the validation of the mathematical model, tests were made in these physical models in the scale of 1:5 to the industrial equipment. The flow monitoring was done by using ordinary camera. The results of the oil thickness obtained in the physical model could validate the results obtained in mathematical modeling. The results showed that the oil thickness near the ladle wall have the least thickness of the oil layer. And the oil between the upleg and the ladle wall were smaller and decrease as the gas flow increases.

Keywords: RH degasser; Multiphase flow; Slag thickness.

Engenheiro Metalurgista, Doutor em Engenharia Metalúrgica, Professor do Departamento de Materiais do Centro Federal de Educação Tecnológica de Minas Gerais (CEFET-MG), Belo Horizonte, Minas Gerais, Brasil.

2 Engenheiro Metalurgista, Ph.D. em Engenharia Metalúrgica, Professor do Departamento de Engenharia Metalúrgica e Materiais da Universidade Federal de Minas Gerais (UFMG), Belo Horizonte, Minas Gerais, Brasil. 


\section{INTRODUÇÃO}

O escoamento multifásico encontra-se presente em vários processos da produção do aço. O desgaseificador $\mathrm{RH}$ se destaca pela injeção de gás e pela intensa agitação do aço. Devido a essa intensa agitação o Rh é considerado um reator metalúrgico de mistura perfeita. Nos últimos anos, houve um aumento das abordagens na literatura sobre o escoamento multifásico neste equipamento. Isto se deve principalmente à grande necessidade de se modelar os processos com injeção de gás e o comportamento da escória. LI e TSUKIHASHI (2005)[1], desenvolveram um sistema com diversas forças de não-arraste atuando na fase dispersa. GENG et al. (2010)[2] utilizaram a simulação matemática do escoamento em um modelo físico do desgaseificador $\mathrm{RH}$ para estudar a relação da taxa de circulação e a injeção de gás. No entanto, nenhum autor estudou o efeito da vazão de gás na espessura da escória. No presente trabalho foi feito um estudo do escoamento multifásico no desgaseificador $\mathrm{RH}$ através do estudo do modelo físico na escala de 1:5 em relação à escala real. $A$ análise foi feita utilizando o modelamento matemático do modelo físico das fases água/óleo/ar. O acompanhamento do escoamento foi feito através de filmagens utilizando câmera comum.

\section{MATERIAIS E MÉTODOS}

Foi desenvolvido um modelo matemático do escoamento tridimensional trifásico água/ar/óleo aplicada ao modelo físico do desgaseificador $\mathrm{RH}$ construído na escala de 1:5 do desgaseificador $\mathrm{RH}$ industrial. As características do modelo físico do desgaseificador $\mathrm{RH}$ e as condições de injeção de gás são apresentadas na figura 1 .

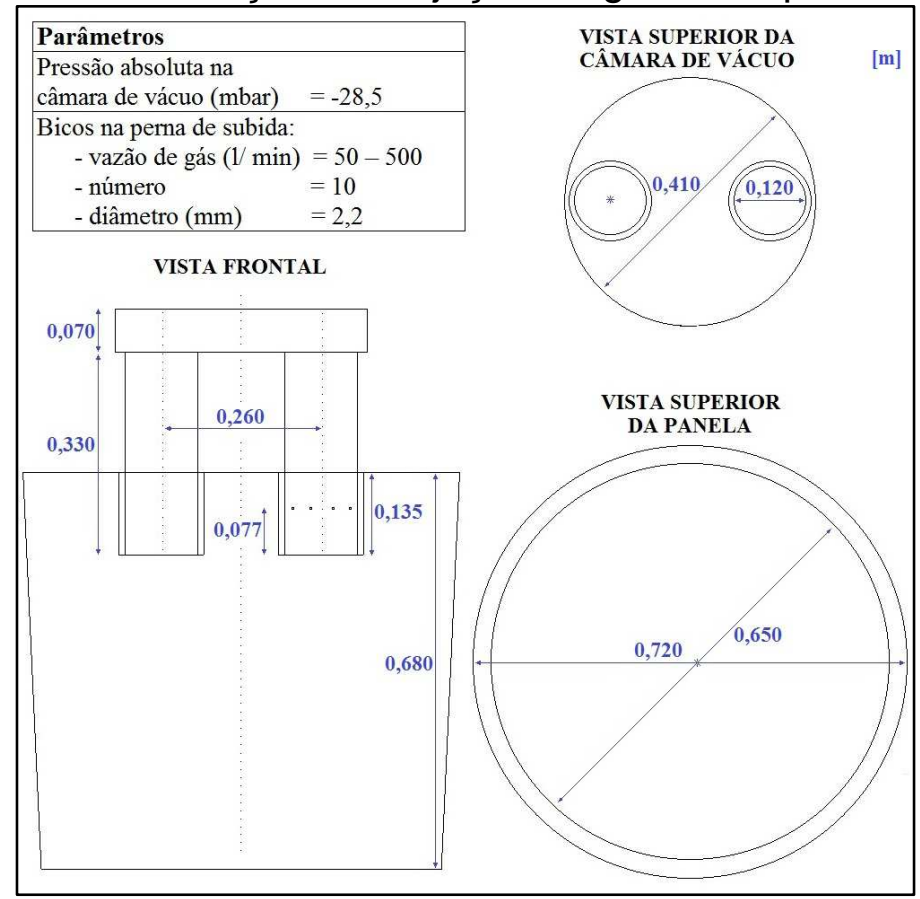

Figura 1 - Desenho esquemático do desgaseificador $\mathrm{RH}$.

O número e o diâmetro dos bicos foram utilizados de acordo com as condições encontradas na indústria. As similaridades dinâmica e cinemática foram estabelecidas em função dos números adimensionais de Froude e de Froude modificado. Utilizando a similaridade desses grupos adimensionais no modelo físico 
com o equipamento industrial, pode-se encontrar a relação da vazão de gás injetado e dos diâmetros dos bicos de injeção. As propriedades das substâncias utilizadas na simulação são apresentadas na tabela 1.

Tabela 1 - Propriedades das substâncias utilizadas no modelamento matemático do escoamento no modelo físico.

\begin{tabular}{llll}
\cline { 2 - 4 } & Ar & Água & Óleo 15W40 \\
\hline Densidade (kg/m $\mathbf{m}^{\mathbf{3}}$ ) & Gás ideal [3] & $997[3]$ & $880[4]$ \\
\hline Viscosidade Dinâmica (kg/m.s) & $1,831 \times 10^{-5}[3]$ & $8,9 \times 10^{-4}[3]$ & $0,0942[5]$ \\
\hline Calor Específico (J/kg.K) & $1004,40[3]$ & $4181,70[3]$ & $1673,60[6]$ \\
\hline
\end{tabular}

As forças de arraste foram introduzidas no termo fonte da equação de conservação de quantidade de movimento da abordagem Euleriana. O modelo de arraste entre as fases ar/água, ar/óleo e água/óleo adotados foi o de Grace e o diâmetro das partículas da fase dispersa igual a três milímetros (LI e TSUKIHASHI, 2005). A tabela 2 mostra as tensões interfaciais das fases utilizadas para simulação do modelo de arraste de Grace.

Tabela 2 - Tensões interfaciais do sistema ar/água/óleo.

\begin{tabular}{|l|c|}
\hline & Tensão interfacial ( $\mathbf{N} / \mathbf{m})$ \\
\hline Ar/Água & $0,08[7]$ \\
\hline Ar/Óleo & $0,02936[8]$ \\
\hline Água/Óleo & $0,033[9]$ \\
\hline
\end{tabular}

As equações de conservação foram discretizadas segundo o esquema "Upwind" (PATANKAR, 1980) [10]. Foram utilizados fatores de relaxação para viabilizar a convergência dos resultados através do controle de escala de tempo para o estado estacionário e transiente. Para a solução das equações, obtenção e análise dos resultados foi utilizado o software comercial de fluidodinâmica computacional da ANSYS. Na solução das equações de conservação relativas ao escoamento de fluidos foi estipulado como critério de convergência RMS ("Root Mean Square") o valor de $10^{-6}$. Para confiabilidade dos resultados foi feito o estudo da independência das malhas. Este estudo visa determinar a malha a partir da qual refinamentos não alteram significativamente os resultados obtidos. Foram utilizadas curvas de taxa de circulação para as vazões de 100 a 500 Nl/min como critério de escolha da melhor malha.

\subsection{Condições de Contorno Adotadas no Desgaseificador RH}

As condições no contorno foram estabelecidas de acordo com as condições físicas nos contornos do domínio do $\mathrm{RH}$. Foram consideradas as seguintes condições de contorno do desgaseificador $\mathrm{RH}$ industrial e do seu modelo físico:

- Paredes: condição de não-escorregamento para os líquidos. Para os gases foi considerada a condição de escorregamento livre ("free slip");

- Superfície livre da panela: a superfície livre da panela foi considerada plana e uma condição de abertura foi adotada;

- Superfície Livre ao Vácuo: na superfície livre ao vácuo foi considerada uma condição de contorno de saída denominada de condição de desgaseificação, e para a fase líquida esta superfície foi considerada como uma condição de escorregamento livre; 
- Bicos de Injeção de Gás: nos bicos de injeção de gás foi considerada a condição de entrada para os gases. As vazões mássicas de entrada de ar para o modelo físico foram de 200, 327 e 409 l/min, de acordo com a similaridade da vazão utilizada nos três estágios de tratamento do aço líquido na indústria.

\subsection{Filmagens da Região Ar/ Água/ Óleo na Panela}

As filmagens feitas para observação do comportamento do sistema trifásico ar/água/óleo foram feitas utilizando com câmeras comuns. Para uma melhor observação do sistema, foi adicionado ao óleo um corante azul. De acordo com dados industriais a camada de escória possui entre 4 a 6 centímetros de espessura. No presente estudo foi considerada a espessura de 5 centímetros como espessura padrão. Considerando a similaridade geométrica de 1:5, foi utilizada a espessura do óleo de 1 centímetro nas filmagens, como mostra a figura 2. nesta mesma figura mostra os posicionamentos das câmeras que foram feitas as filmagens. Foram obtidas imagens da região lateral da perna de subida (posição 2), região lateral da perna de descida (posição 3), região superior entre a perna de subida e a parede da panela (posição 4), região superior entre a perna de descida e a parede da panela (posição 5) e, por fim, uma vista geral com a câmera posicionada na região abaixo do modelo físico (posição 1). Foram feitas filmagens convencionais simultâneas para as posições 2 e 4 e para as posições 3 e 5, para observar como a espessura do óleo se comporta em relação a região de formação do "olho". Para visualização dos resultados, foram tiradas 6 imagens no tempo de filmagem de 1 minuto.

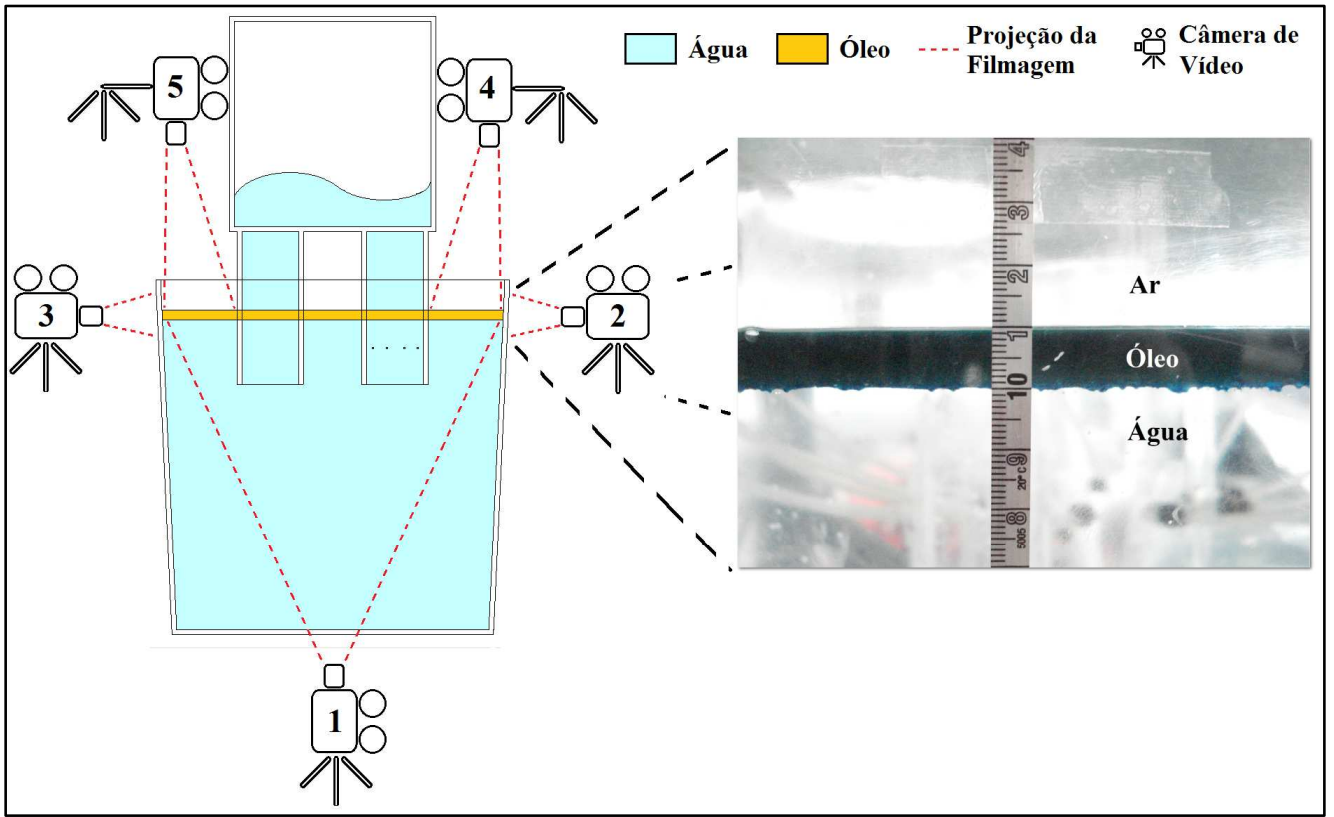

Figura 2 - Posicionamentos das câmeras nas filmagens do sistema ar/água/óleo.

O tratamento das filmagens do sistema trifásico ar/água/óleo foi feito visando obter a espessura da camada de escória nas regiões entre as pernas do desgaseificador $\mathrm{RH}$ e a panela. Para este tratamento foram capturadas 15 imagens aleatórias obtidas nas posições 2 e 3, em intervalos de tempo iguais no total de 1 minuto de filmagem. No tratamento das imagens foi utilizado um "software" aberto denominado "Image J" e foi encontrado que 1 centímetro representava 20,809 pixels da imagem tratada. 


\section{RESULTADOS E DISCUSSÃO}

Encontrou-se que a malha com 1.000.000 de elementos de volume foi a mais adequada, pois refinamentos posteriores não afetaram a taxa de circulação segundo o critério proposto.

\subsection{Simulações para o sistema Ar/Água/Óleo}

A análise do sistema trifásico ar/água/óleo foi feita considerando a superfície livre da panela em contato o ar atmosférico e a superfície livre da câmara ao vácuo plana sem interface com o ar. A simulação foi baseada em um estudo feito com um óleo de propriedades conhecidas e utilizado para simular a escória do desgaseificador $\mathrm{RH}$.

A figura 3 mostra uma comparação dos vetores de velocidade para o escoamento da água considerando as vazões de gás de (a) $200 \mathrm{l} / \mathrm{min}$, (b) $327 \mathrm{l} / \mathrm{min}$ e (c) 409 $\mathrm{l} / \mathrm{min}$, respectivamente. Também se observa os vetores de velocidade a partir de um corte na região inicial de contato água/óleo das vistas lateral e superior. $O$ escoamento da água é modificado de acordo com a vazão de gás. Isto ocorre devido às diferentes taxas de circulação proporcionada pelas diferentes vazões de ar, pois à medida que se aumenta o fluxo descendente da água na perna de descida a velocidade da água no interior $\mathrm{RH}$ aumenta. Nota-se que com a modificação do fluxo na região de contato inicial água/óleo, o óleo tende a se concentrar em diferentes regiões da superfície de acordo com o escoamento da água, como é mostrado na figura 4, onde (a), (b) e (c) representam as vazões de gás de 200, 327 e 409 I/min, respectivamente. De acordo com os cortes, as regiões em que não há a ocorrência de óleo, são as regiões entre a perna de subida e a parede da panela e entre a perna de descida e a parede da panela. Isto ocorre devido a alta turbulência, expondo a água ao ar atmosférico.

As taxas de circulação para as vazões de gás de 200, 327 e $409 \mathrm{l} / \mathrm{min}$ são de 6,11; 6,73 e $7,14 \mathrm{~kg} / \mathrm{s}$, respectivamente. As velocidades médias no plano de simetria do modelo físico para as vazões de 200, 327 e 409 I/min são de 1,27; 2,06 e 2,53 m/s.

De uma forma geral, o óleo tende a concentrar-se na região próxima à perna de subida devido à sucção promovida nesta região. Estas diferenças na ocupação do óleo ocorrem pela maior turbulência no contato água/óleo, promovida pelas maiores taxas de circulação da água.

A figura 5 mostra imagens do comportamento do óleo para as vazões de 200, 327 e $409 \mathrm{l} / \mathrm{min}$, com a câmera localizada na posição 1, vista de baixo do modelo físico do $\mathrm{RH}$. Nas imagens tratadas, as regiões mais claras são regiões onde ocorre uma maior turbulência no contato ar/água/óleo, havendo a diminuição e possível extinção da camada de óleo naquela região ocorrendo muitas vezes a abertura de "olhos", no qual a água entra em contato com o ar atmosférico. Nota-se que nas regiões mais próximas das paredes, ocorre a mais alta turbulência principalmente nas regiões em que as pernas estão mais próximas da parede da panela. Isto ocorre devido à recirculação da água que proveniente da câmara de vácuo passa pelo fundo da panela e volta para a superfície. 


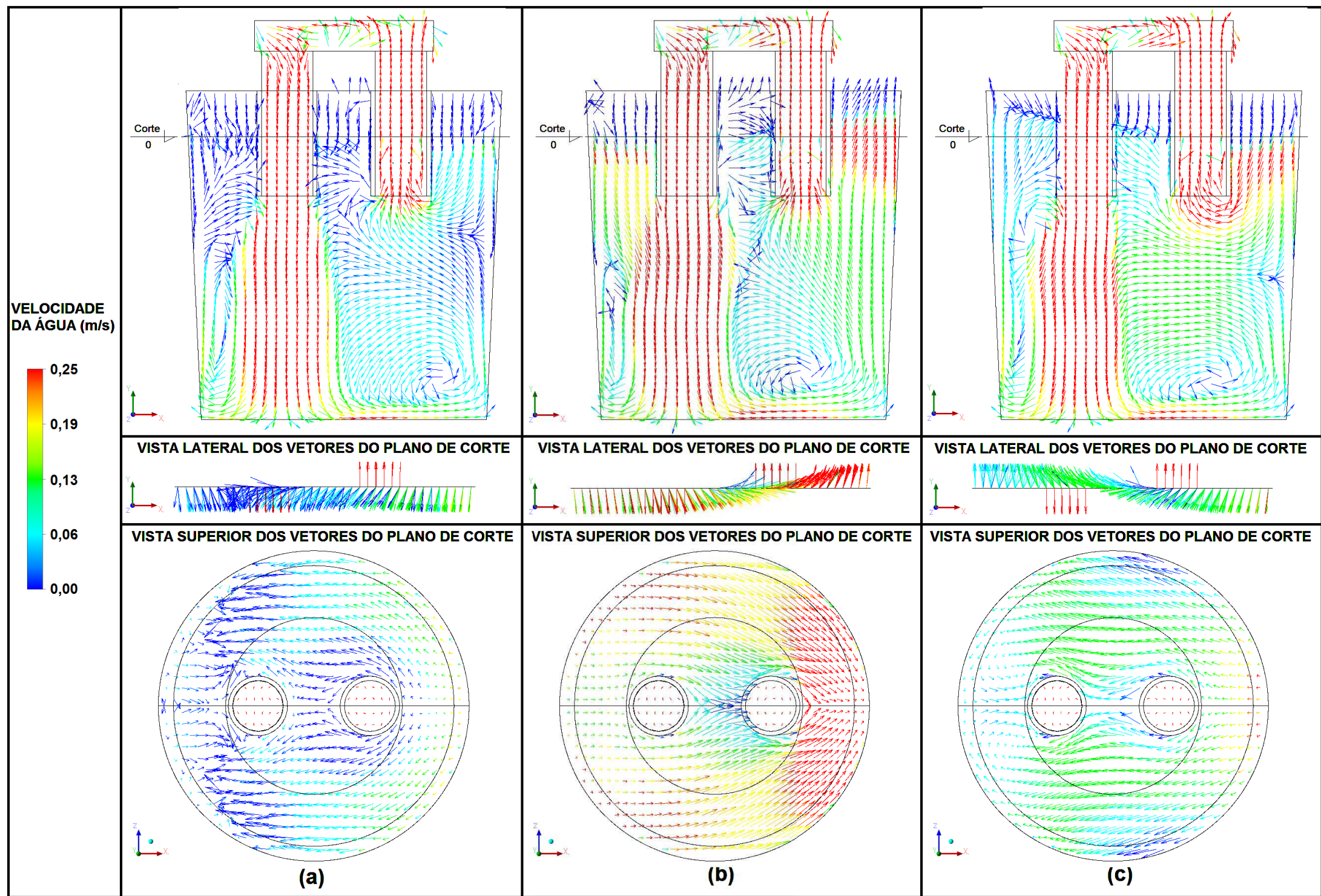

Figura 3 - Distribuição dos vetores de velocidade da água no plano de simetria e para as vistas lateral e superior a partir de um corte horizontal da seção do contato inicial água/óleo para a vazão de gás de 200, 327 e 409 l/min. 

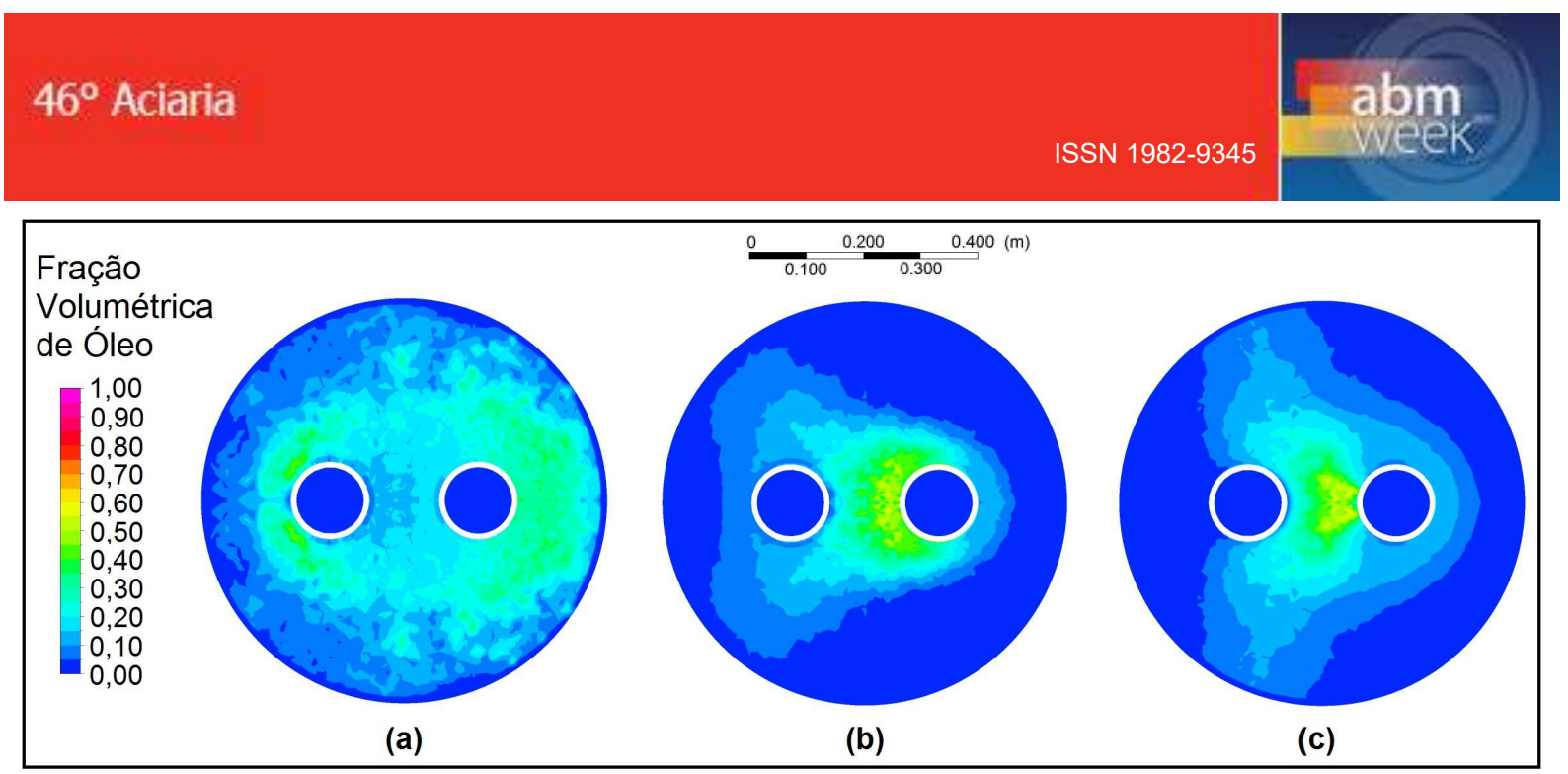

Figura 4 - Cortes transversais da fração volumétrica de óleo para a seção de corte na linha do óleo em contato com a água para o sistema trifásico sem a representação da superfície livre ao vácuo, sendo (a), (b) e (c) para as vazões de gás de 200, 327 e $409 \mathrm{l} / \mathrm{min}$, respectivamente.

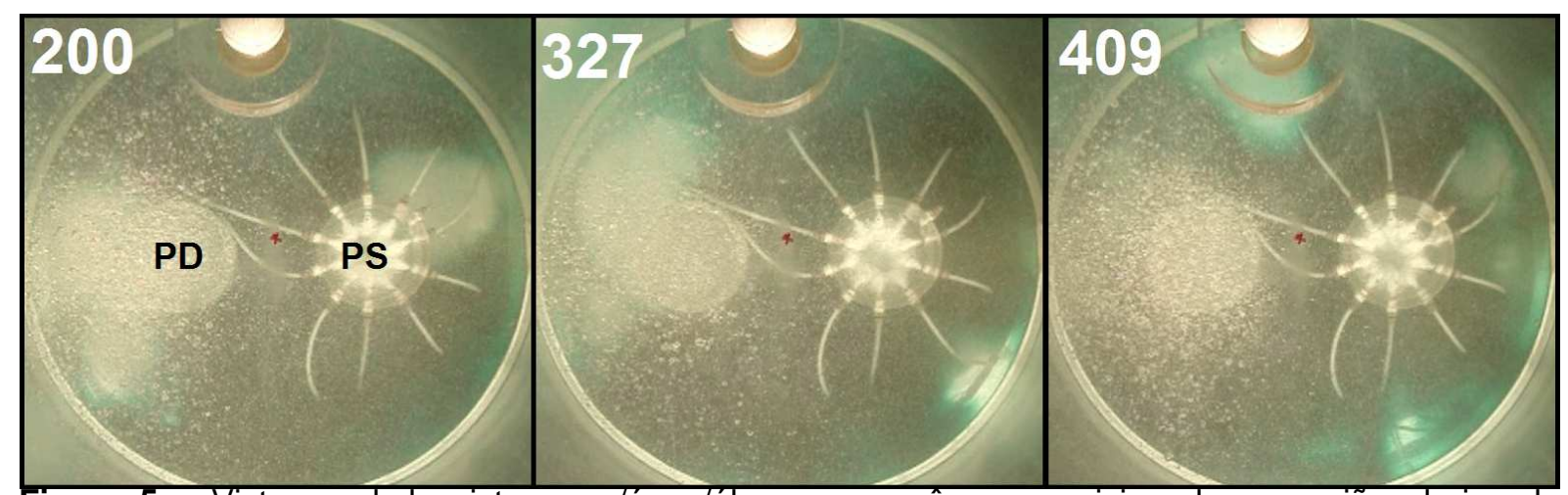

Figura 5 - Vista geral do sistema ar/água/óleo com a câmera posicionada na região abaixo do modelo físico (posição 1) para as vazões de 200, 327 e 409 l/min. O termo PS refere-se à perna de subida e o termo PD à perna de descida.

Nas imagens obtidas nota-se que à medida que se aumenta a vazão de gás, os "olhos" aumentam de tamanho, principalmente na região entre a perna de descida e a panela. A água quando passa pela câmara de vácuo transporta certa quantidade de bolhas e estas bolhas quando flotam na região próxima à perna de descida ajudam na formação dos "olhos". A turbulência na superfície ar/água/óleo nos entornos da perna de descida é muito maior que na perna de subida, de forma que a formação de "olho" na perna de subida quase não ocorre. O resultado da simulação matemática para a vazão de ar de $409 \mathrm{l} / \mathrm{min}$ mostra que a velocidade é ascendente nesta região, possibilitando assim uma maior formação de "olho".

As filmagens nas regiões laterais e superiores, onde ocorre a maior turbulência, foram feitas simultaneamente utilizando câmeras comuns. As imagens foram obtidas das filmagens da região lateral da perna de subida (posição 2), região lateral da perna de descida (posição 3), região superior entre a perna de subida e a parede da panela (posição 4), região superior entre a perna de descida e a parede da panela (posição 5). Foram utilizadas apenas 3 vazões nestas filmagens a de 200, 327 e 409 I/min.

A figura 6 mostra os resultados para as posições de filmagens 2 e 4, na perna de subida e 3 e 5 na perna de descida para as vazão de 327 l/min. Para as vazões de 200 e 409 l/min também foram feitas estas filmagens. 


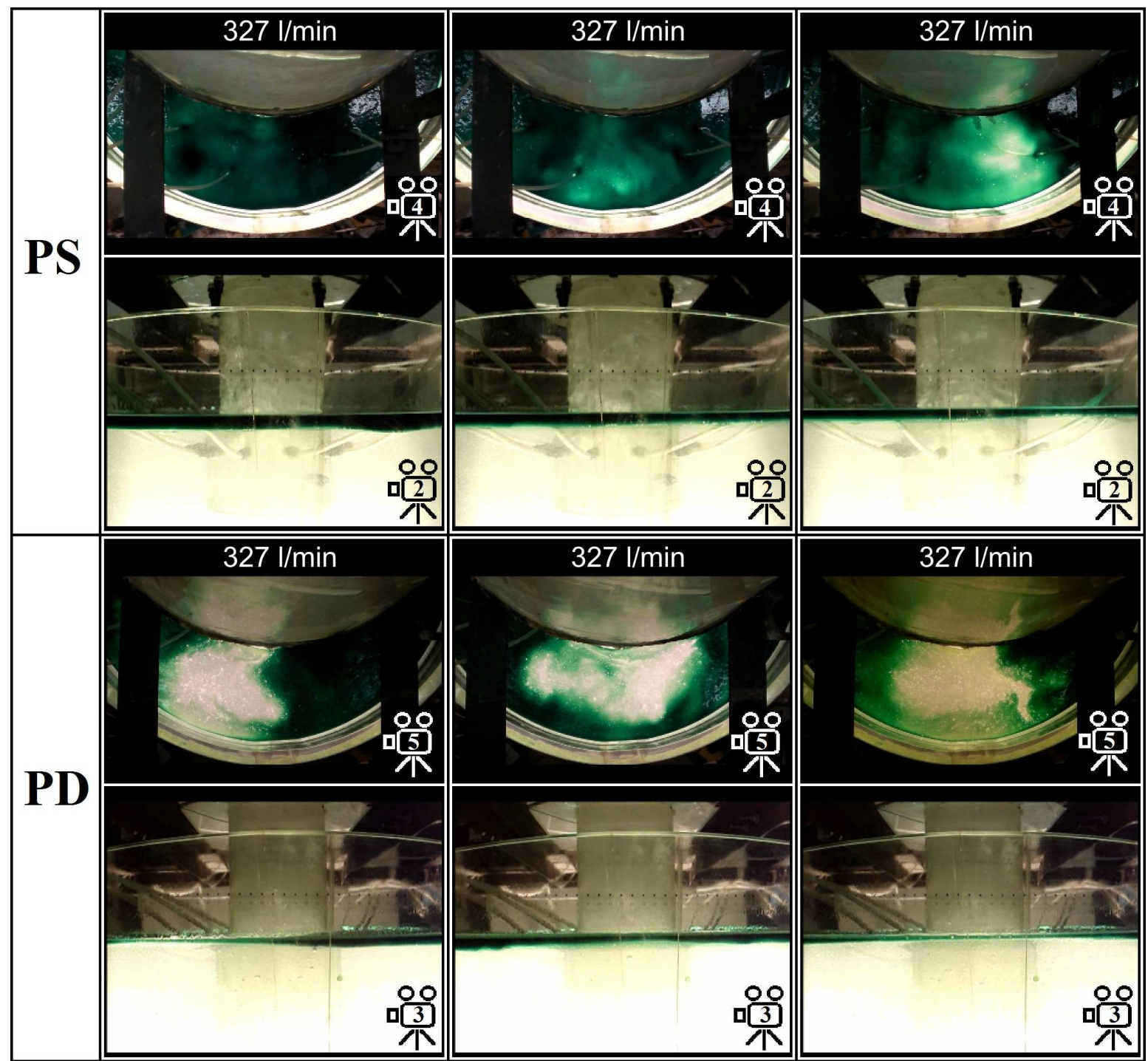

Figura 6 - Resultados de imagens das filmagens simultâneas feitas na perna de subida (vista lateral da perna de subida (câmera 2) e vista superior da região entre a perna de subida e a parede da panela (câmera 4)) e perna de descida (vista lateral da perna de descida (câmera 3) e vista superior da região entre a perna de descida e a parede da panela (câmera 5)) para a vazão de 327 l/min.

Nestas figuras são apresentadas 3 imagens para cada posicionamento das câmeras, de forma que se possa observar as imagens simultâneas das posições laterais e superiores das câmeras. O "olho" forma-se mais intensamente na região entre a perna de descida e a parede da panela. Há uma tendência do "olho" diminuir na região entre a perna de subida e parede da panela à medida que se aumenta a vazão de gás. Isto é explicado pelo fato da abertura do "olho" aumentar na região da perna de descida devido ao aumento da vazão de gás e com isso empurrar a escória para outras regiões.

Analisando as imagens, percebe-se que a espessura do óleo diminui onde forma-se o "olho" e nas regiões mais claras onde há a tendência da formação do "olho". Para isto foram feitas medidas da espessura do óleo nas imagens das regiões laterais da perna de subida e perna de descida em 3 posições diferentes: posição 1 (afastada 15 centímetros a esquerda do centro da imagem), posição 2 (posição central) e posição 3 (afastada 15 centímetros a direita do centro da imagem). Para cada posição foram retiradas 10 medidas de espessura. 
A figura 7 mostra um gráfico da espessura versus a vazão de gás nas regiões entre a parede e a perna de subida (PS) e entre a parede e a perna de descida (PD) para as vazões de gás de 200, 327 e $409 \mathrm{l} / \mathrm{min}$. De acordo com a figura, a espessura média do óleo na região entre a parede da panela e a perna de subida é menor para vazões menores e teve a tendência de aumentar a medida que se aumentava a vazão de gás. Estes valores das espessuras e seus desvios padrões para as vazões de 200, 327 e $409 \mathrm{l} / \mathrm{min}$ são $(0,72 \pm 0,14 \mathrm{~cm}),(0,92 \pm 0,15 \mathrm{~cm})$ e $(1,00 \pm 0,18 \mathrm{~cm})$, respectivamente. Já a espessura média do óleo na região entre a parede da panela e a perna de descida teve uma leve tendência de queda à medida que se aumentava a vazão de gás e seus valores ficaram abaixo da espessura inicial de 1 $\mathrm{cm}$. Os valores das espessuras e seus desvios padrões para as vazões de 200, 327 e $409 \mathrm{l} / \mathrm{min}$ nesta região são $(0,64 \pm 0,31 \mathrm{~cm}),(0,52 \pm 0,20 \mathrm{~cm})$ e $(0,54 \pm 0,22 \mathrm{~cm})$, respectivamente. Desta forma, comprova-se que com o aumento da vazão de gás diminui-se a espessura do óleo na região entre a perna de descida e a parede da panela e com isso o óleo é empurrado para outras regiões afetando a região entre a perna de subida e parede da panela. A compreensão deste efeito mostra indícios de que no desgaseificador $\mathrm{RH}$ industrial, há a possibilidade de formação de "olho" entre a perna de descida e a panela. Mesmo que este efeito não ocorra devido a uma espessa camada de escória, a perda térmica nesta região deve ser maior pela diminuição na espessura da camada de escória.

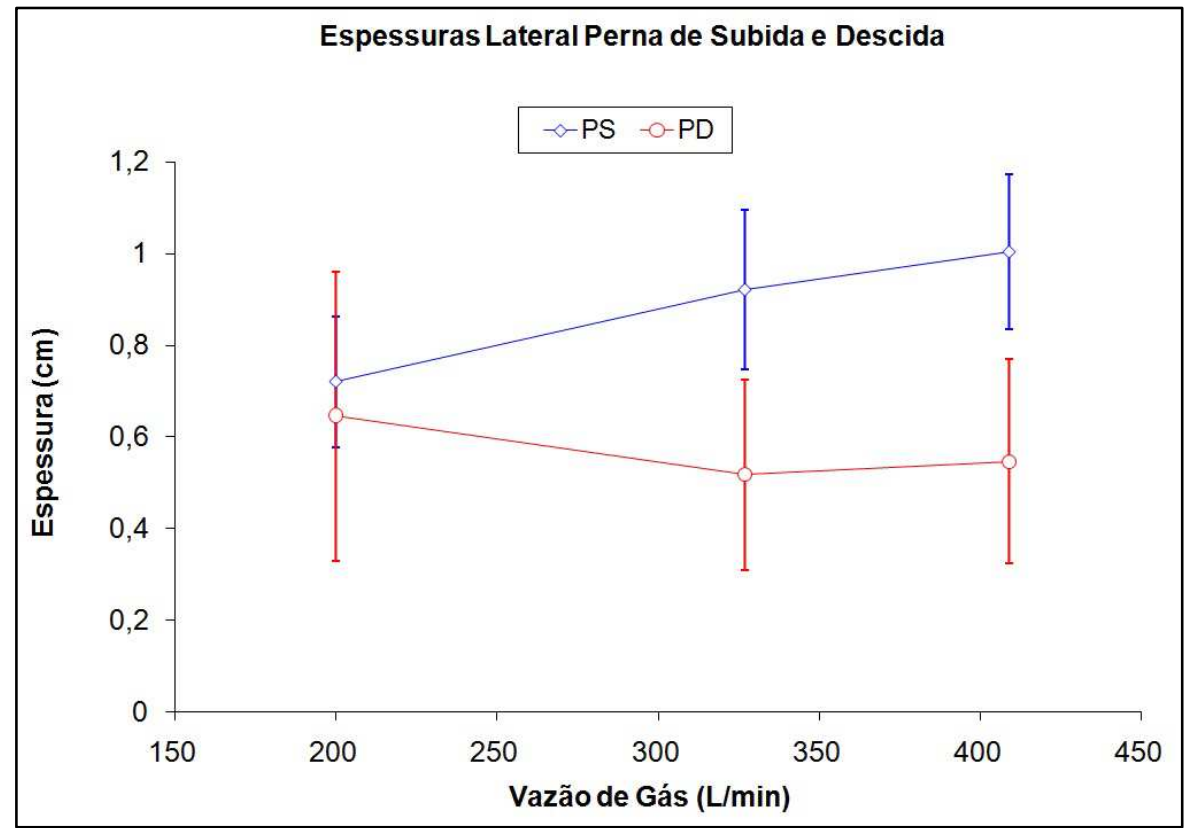

Figura 7 - Média das espessuras do óleo para as regiões da perna de subida e perna de descida para as vazões de gás de 200, 327 e 409 I/min.

\section{CONCLUSÃO}

Nota-se nos resultados do escoamento matemático do desgaseificador $\mathrm{RH}$ diferentes padrões de escoamento. Os resultados do escoamento matemático foram comprovados por resultados de análise de imagens em filmagens do modelo físico. O óleo se localiza em posições mais centrais e distante da parede da panela. Desta forma, ocorreu o aparecimento do "olho" expondo a água à atmosfera. Este efeito ocorreu principalmente nas regiões próximas às paredes da panela. A espessura do óleo foi a menor entre a parede da panela e as pernas do $\mathrm{RH}$, sendo que nas proximidades da perna de subida esta espessura foi a menor que se encontrou nos 
resultados apresentados. No entanto, na indústria esse efeito não é observado. Isso porque a escória possui viscosidade variável com a temperatura e a temperatura externa no ambiente de trabalho na indústria é a temperatura ambiente. Porém, a camada nessas regiões devem ser mais finas e portanto ocorrer uma maior perda de calor nessas regiões.

\section{REFERÊNCIAS}

$1 \quad$ Li B \& Tsukihashi F. Effect of Rotating Magnetic Field on Two-Phase Flow in RH Vacuum Degassing Vessel. ISIJ International, 2005; 45(7): 972-978.

2 Geng DQ, Lei H. e He JC. Numerical Simulation of the Multiphase Flow in the Rheinsahl-Heraeus (RH) System. Metallurgical and Materials Transactions B. 2010; 41B: 234-247.

$3 \quad$ ANSYS $^{\circledR}$ CFX ${ }^{\mathrm{TM}}$, Release 11.0, Library Materials, Pre User's Guide, ANSYS, Inc.

$4 \quad$ Ficha de dados Total Multagri TM 15W40.

5 Carvalho MJS. Efeitos do Lubrificante e Aditivos na Economia de Combustível Diesel, Universidade Federal do Rio de Janeiro, 2010.

6 Manual Aalborg Industries, Calor Específico (temperatura abaixo de 100), Petrópolis, Rio de Janeiro, 2011.

7 Rabockai, T. Físico-Química de Superfícies. Instituto de Química de São Paulo. São Paulo, SP. Washington D.C.1979.

8 Mendonça CG, Caetano CG, Mendonça CG. Tensão Superficial Estática de Soluções Aquosas com Óleos Minerais e Vegetais Utilizados na Agricultura. Eng. Agríc. Jaboticabal. 2007; 27:16-23.

9 Universidade Federal de Sergipe[página na internet]. Sergipe: UFS, 2011 [acesso em Setembro de 2011]. Disponível em: http://www.fisica.ufs.br.

10 Patankar SV. Numerical Heat Transfer and Fluid Flow - Series in Computational Methods in Mechanics and Thermal Sciences. Hemisphere Publishing Corporation. USA; 1980. 